\title{
A PROSPECTIVE STUDY OF ACUTE POISONINGS IN A SAMPLE OF GREEK PATIENTS
}

\author{
Triada Exiara ${ }^{1}$, Thomas A. Mavrakanas ${ }^{2}$, Leonidas Papazoglou ${ }^{1}$, Dimitris Papazoglou ${ }^{1}$, Dimitris Christakidis ${ }^{3}$, \\ Efstratios Maltezos ${ }^{1}$ \\ ${ }^{1}$ Second Department of Internal Medicine, General Regional Hospital of Alexandroupoli, Democritus University of Thrace, Greece \\ ${ }^{2}$ First Laboratory of Pharmacology, Medical School, Aristotle University of Thessaloniki, Greece \\ ${ }^{3}$ Department of Internal Medicine of the Regional Health System, General Regional Hospital of Alexandroupoli, Greece
}

\begin{abstract}
SUMMARY
Objectives. Acute poisoning is one of the most common situations managed in the emergency department. Significant differences have been reported concerning the prevalence and etiology of poisoning. This study aims to present the epidemiologic and clinical characteristics of poisonings in the region of Thrace in Northern Greece, where no similar studies have been performed.

Methods. A prospective study was carried out in our hospital's emergency department during 4 years (1999-2003). A total of 223 adult patients were admitted with acute poisoning, 87 males (39\%) and 136 females (61\%).

Results. Mean age of male and female patients was 37.1 years (standard deviation 16.1) and 33.4 years (standard deviation 14.5), respectively. Intoxications were more common in summer (34.1\%). The median time between poisoning and presentation was 4 hours. Poisonings were more common in the urban population (64.1\%). Psychotropes were the leading cause of poisoning in patients with a psychiatric disease (74.1\%) and analgesics in all the other patients groups (34.8\%). The clinical status on admission was: conscious (45.7\%), confused (35.4\%), precoma/ coma (18.9\%). Haemodialysis was performed only in one patient and respiratory support was necessary in 10 patients. An antidote was administrated in 73 patients. Median hospital stay was 1 day. Two patients died (0.9\%).

Conclusions. Poisoning's aetiology varies significantly in different countries. Previous suicide attempts are common in these patients. Precipitating factors can be major depressive, or dysthymic disorders. The mortality rate is low.
\end{abstract}

Key words: poisoning, adults, epidemiology, clinical status

Address for correspondence: T. A. Mavrakanas, 61 Kifisias street, 54248, Thessaloniki, Greece. E-mail: thomas_mavrakanas@yahoo.fr

\section{INTRODUCTION}

Self-poisoning is one of the most common situations managed by emergency care departments (1). The incidence of intoxications has increased up to 157 per 100,000 inhabitants in certain European countries (2). Poisonings represent up to $3.8 \%$ of the overall admissions in a medical department (3) and $0.7 \%$ of all emergency admissions (4).

Most patients presenting with intoxication are below the age of 40 years. Mean age is reported to be 33 years in Thessaloniki, Greece and the most frequent age group is 23-30 (3). Most European studies show a similar age variation. Mean age is 35.3 (Standard deviation - SD \pm 13.7) years in Vienne, France (1), 41 years in Frankfurt am Main, Germany (5), 36 years (SD: \pm 15 , median: 32) in Madrid, Spain (2), 36 years in Barcelona, Spain (6), whereas, in Turkey, $63.6 \%$ of the patients were below the age of 25 (4).

Poisoning is found to be more common in females in most European countries. Females prevail over males in Belgium (56\%) (7), Scotland (8), Greece (female-to-male ratio 1.97 to 1) (3) and Turkey (female-to-male ratio 3:1) (4). However, an equal prevalence is reported in Finland(9) and males prevail over females (51.3\%) in a Spanish study (10).

Significant differences have also been reported about the etiology of poisoning and the medical history of this group of patients $(1,3,7,8)$. Although hospitalization at the intensive care unit is needed in many circumstances $(5,6)$, mortality rate is rather low $(2,7,9)$.

The aim of our study is to present the epidemiological characteristics of poisonings in the region of Thrace in Northern Greece, where no similar studies have been performed as far as we know. We studied the etiology, the medical history of these patients and their need for a specific treatment. A comparison was attempted with other European countries, in order to investigate the specific features of the Greek population.

\section{METHODS}

We carried out a prospective study concerning adult patients presenting with acute poisoning to the Regional General Hospital of Alexandroupoli. In four years time (1999-2003), a total of 223 patients were admitted to the emergency medical department of our hospital for an episode of acute poisoning. This hospital is responsible for all the inhabitants of the eastern part of Thrace, a Northern Greek province (about 100,000 inhabitants).

This sample of 223 patients consisted of 87 males (39\%) and 136 females (61\%), aged between 14 and 90 years. These patients represented $3.8 \%$ of the overall admissions to the medical departments for the same time period. 
Patients were monitored upon admission in order to assess their clinical status. After a thorough clinical and neurological examination, the patients' hepatic, respiratory and renal functions were closely monitored in order to identify the presence of hepatic, respiratory, renal or multi-organ failure. Specific antidotes, respiratory support or haemodialysis were available when necessary.

When clinical status permitted an interview, patients were questioned about their age, address, medical history, the substance responsible for the poisoning, the existence of previous suicide attempts and the exact time of the poisoning. They were assured that these data would be confidential.

For the statistical analysis of patients' age in both sex groups, the $t$ distribution was used, as the observations were sampled from a population with a normal distribution (assessed with a normal plot) and the variances of age in males and females were the same $(\mathrm{F}=1.22, \mathrm{p}=0.15)$. For the time between ingestion of poison and presentation, as well as the time of hospitalization, a confidence interval for the median was used, because both variables were considerably skewed. For the other confidence intervals (95\% CI), the normal approximation to the binomial distribution was used (11).

\section{RESULTS}

Poisonings were more common in females. The $95 \%$ confidence interval was 32.6 to $45.4 \%$ for males and 54.6 to $67.4 \%$ for females.

The mean age of male patients was 37.1 years (SD 16.1 - 95\% CI: 33.6 to 40.5 years). The mean age of female patients was 33.4 years (SD 14.5 - 95\% CI: 31 to 35.9 years). The mean age difference between sexes was 3.7 years (95\% CI from -0.5 to 7.7 years, $\mathrm{p}=0.08$ ). Therefore, female patients were slightly younger than males, although not at the level of significance.

The monthly incidence of poisonings is shown in Table 1 . Intoxications were more common in summer (34.1\%) (June, August and July).

The mean time between ingestion of poison and presentation was 4.8 hours ( $\mathrm{SD} \pm 4.87$ ). The median time was 4 hours (95\% CI for the median: 3 to 4 hours).

Table 1. Monthly incidence of poisoning

\begin{tabular}{|l|c|}
\hline Month & Cases \\
\hline January & $19(8.5 \%)$ \\
\hline February & $17(7.6 \%)$ \\
\hline March & $21(9.4 \%)$ \\
\hline April & $17(7.6 \%)$ \\
\hline May & $21(9.4 \%)$ \\
\hline June & $28(12.6 \%)$ \\
\hline July & $23(10.3 \%)$ \\
\hline August & $25(11.2 \%)$ \\
\hline September & $17(7.6 \%)$ \\
\hline October & $14(6.3 \%)$ \\
\hline November & $10(4.5 \%)$ \\
\hline December & $11(5.0 \%)$ \\
\hline
\end{tabular}

Eighty of the patients (35.9\%) lived in rural areas and 143 (64.1\%) in urban environments, the $95 \%$ CI being 29.6 to $42.2 \%$ for the rural population and 57.8 to $70.4 \%$ for the urban population. Therefore, poisonings were more common in the urban population.

Substances responsible for the poisoning are shown in Table 2. In 41 cases, more than one toxic substances were taken. The more common combinations were psychotropes with alcohol (13 patients) and analgesics with alcohol (8 patients).

Medical history of the patients is shown in Table 3. Previous suicide attempts were reported in 14 patients (6.3\%) and 12 of them had had a diagnosed psychiatric disease. Psychotropes were the more common cause of poisoning in the patients with a psychiatric disease: 80 cases (74.1\%). Analgesics were the more common cause of poisoning in all the other patient groups: 40 cases (34.8\%).

The clinical status of the patients on arrival is shown in Table 4. Twenty-two out of the 42 patients in precoma or coma had been intoxicated by opiates (52.4\%). It is remarkable that 22 out of the 23 patients intoxicated by opiates were in precoma or coma.

Haemodialysis was performed in one patient and respiratory support was needed in 10 patients. Nineteen patients (8.5\%) developed multi-organ failure. An antidote was administrated in 73 patients (32.7\%). The median hospital stay was 1 day $(99 \%$ CI for the median: 1 to 2 days). Two patients died (0.9\%). Both of them had taken a large quantity of Paraquat ${ }^{\oplus}\left(\mathrm{N}, \mathrm{N}^{\prime}\right.$-dimethyl4,4'-bipyridinium dichloride, a herbicide).

\section{DISCUSSION AND CONCLUSIONS}

Poisoning is found to be more common in females in most European countries. A female to male ratio of 1.56 was also found in our region. Our data also support the fact that most patients presenting with intoxication are below the age of 40 years. We also found that poisoning is more common in the urban population, a common feature in Greece (3).

The delay from ingestion of the poison to presentation is reported to be equal or longer than 4 hours $(3,9)$, as well as in our study.

A seasonal distribution is present in our population, with a peak in summer and June being the month with the highest incidence. A similar summer peak (37.5\% of cases) has also been reported in the Greek population with July being the month with the highest incidence (23.7\%) (3). On the other hand, the month with the highest incidence of poisoning in Spain was February (10). This discrepancy is probably due to the different aetiology of poisoning in different countries.

Psychotropes were the cause of the intoxication in most of our cases. Psychopharmaceuticals are also reported to be the leading cause in another Greek study (37.4\%) (3), in France (benzodiazepines - 80\%) (1,12), Belgium (benzodiazepines - 55\%)(7) and Croatia (benzodiazepines - 48\%, antidepressants - 11\%) (13). On the other hand, alcohol was responsible for poisoning in only $11.3 \%$ of our cases. Intoxication with alcohol is reported at low levels in another Greek study (8.4\%) (3) and in Croatia (16\%) (13). However, alcohol was the most common cause of poisoning in Spain (23$32.6 \%)(2,10)$, Belgium (35.8\%)(7), Scotland (63\%)(8) and Finland (66.7\%) (9). Analgesics are the leading cause in Turkey (29.7\%) (4) but are also involved significantly in poisoning in Greece (32.6\%) (3) and Belgium (13.3\%) (7). Opiates and cocaine are responsible for 
Table 3. Patients' medical history

\begin{tabular}{|l|c|c|c|c|c|c|}
\hline \multirow{2}{*}{ History } & \multirow{2}{*}{ No disease } & \multicolumn{3}{|c|}{ Psychiatric } & \multirow{2}{*}{ Context of stress } & \multirow{2}{*}{ Other diseases } \\
\cline { 3 - 6 } & & Psychosis & Depression & Alcoholism & & \\
\hline Cases & $34(15.3 \%)$ & $40(17.9 \%)$ & $61(27.4 \%)$ & $7(3.1 \%)$ & $41(18.4 \%)$ & $40(17.9 \%)$ \\
\hline
\end{tabular}

Table 4. Clinical status of patients upon arrival

\begin{tabular}{|c|c|c|c|c|}
\hline State & Conscious & Confused & Pre-coma & Coma \\
\hline Cases & $102(45.7 \%)$ & $79(35.4 \%)$ & $10(4.5 \%)$ & $32(14.4 \%)$ \\
\hline
\end{tabular}

about $16 \%$ of the cases in Spain and Croatia $(10,13)$. In our region, the opiate intoxication was at rather lower level (9\%).

The patients' clinical status upon arrival is generally good. Serious symptoms (e.g. unconsciousness, insufficient ventilation necessitating intubation, aspiration, convulsions or hypotension) occurred in 15\% of cases in Finland (9). We found a rather high proportion of semi-comatose or comatose patients (18.9\%), also observed in Croatia (29\%) (13).

Previous suicide attempts were reported in $40 \%$ of the patients in Scotland and Croatia $(8,13)$, a much higher proportion than the Greek one (6.3\%). Precipitating factors are found to be major depressive disorders, dysthymic disorders, disorders with depressive mood or impulsive act, the patient's age and sex, concomitant health behaviour risk factors, economic status and quality of health care (14-18).

The mean overall hospitalization time varies between 24 hours and 3.3 days $(3,9)$. In our hospital, only $19 \%$ of the patients were hospitalized for more than 2 days.

Mortality rate is reported to be extremely low: $0.08 \%$ to $0.47 \%$ in Spain (2, 10), 0.3\% in Belgium (7), 2.9\% in a Greek study (3) and no fatalities in a Finnish one (9). We also had only 2 fatalities. However, our study is probably biased, as we had no data about intoxicated patients that died outside hospital never arriving at the emergency department. A similar study in Oslo found that 91.8\% of all deaths by poisoning occur outside hospital(19) and raised the overall mortality rate up to $6 \%$.

It should be noted that the population of our region has a rather low income and there are no major socio-economic differences even between the inhabitants of the rural or urban areas. Therefore, our results are possibly biased towards lower socio-economic populations.

In conclusion, poisoning is a rather common medical emergency. It is more prevalent on young females and usually due to psychotropes or analgesics. As a great proportion of all cases is observed in psychiatric patients, phycisians are encouraged to recommend psychiatric care for people suffering from mental problems or depression. The role of family doctors is very important in the early diagnosis and advice of these patients.

\section{REFERENCES}

1. Lardeur JY, Compain C, Baudier D, Baudier A. Management of self poisoning at an emergency medical center. Presse Med. 2001 Apr 7;30(13):626-30. (In French.)

2. Caballero Vallés PJ, Dorado Pombo S, Brusínt Olivares B, Jerez Basurco B, Medina Sampedro M. The epidemiological surveillance of acute poi- soning in 1997 (a study of 1140 cases from the area south of the Madrid Community). Rev Clin Esp. 1999 Jul;199(7):424-30. (In Spanish.)

3. Hatzitolios AI, Sion ML, Eleftheriadis NP, Toulis E, Efstratiadis G, Vartzopoulos D, et al. Parasuicidal poisoning treated in a Greek medical ward: epidemiology and clinical experience. Hum Exp Toxicol. 2001 Dec;20(12):611-7.

4. Ozköse Z, Ayoglu F. Etiological and demographical characteristics of acute adult poisoning in Ankara, Turkey. Hum Exp Toxicol. 1999 Oct;18(10):614-8.

5. Viertel A, Weidmann E, Brodt HR. Cases of acute poisoning admitted to a medical intensive care unit. Dtsch Med Wochenschr. 2001 Oct 19;126(42):1159-63. (In German.)

6. Nogué S, Marruecos L, Nolla J, Monteís J, Ferrer A, Civeira E. The profile evolution of acute severe poisoning in Spain. Toxicol Lett. 1992 Dec;64-65 Spec No:725-7.

7. Verstraete AG, Buylaert WA. Survey of patients with acute poisoning seen in the Emergency Department of the University Hospital of Gent between 1983 and 1990. Eur J Emerg Med. 1995 Dec;2(4):217-23.

8. Willox DG. Self poisoning. A review of patients seen in the Victoria Infirmary, Glasgow. Scott Med J. 1985 Oct;30(4):220-4.

9. Lapatto-Reiniluoto O, Kivistö KT, Pohjola-Sintonen S, Luomanmäki K, Neuvonen PJ. A prospective study of acute poisonings in Finnish hospital patients. Hum Exp Toxicol. 1998 Jun;17(6):307-11.

10. Bajo Bajo A, Santos Pérez ME, Sanz Ortega F, Zapico Alvarez N, Okatsu KT, García Pérez A, et al. An epidemiological study of acute intoxications and provision of medical-cabinet antidotes. An Med Interna. 1999 Jun;16(6):285-9. (In Spanish.)

11. Altman DG. Practical statistics for medical research. Boca Raton (US): Chapman \& Hall/ CRC; 1999.

12. Lambert H, Manel J, Bellou A, el Kouch S. Morbidity and mortality from acute drug poisoning in France. Rev Prat. 1997 Apr 1;47(7):716-20. (In French.)

13. Prkacin I, Vujanić S, Dabo N, Palcić I, Naumovski-Mihalić S. Cases of acute poisoning admitted to Clinical Hospital Merkur in Zagreb in 1999. Arh Hig Rada Toksikol. 2001 Nov;52(3):315-21.

14. Juárez-Aragón G, Castañón-González JA, Pérez-Morales AJ, Montoya Cabrera MA. Clinical and epidemiological characteristics of severe poisoning in an adult population admitted to an intensive care unit. Gac Med Mex. 1999 Nov-Dec;135(6):669-75. (In Spanish.)

15. Suicide huge but preventable public health problem, says WHO. World suicide prevention day-10 September. Cent Eur J Public Health. 2004 Dec;12(4):196, 200, 206.

16. Easton A, Kiss E, Mowery P. Budapest Student Health Behavior Survey-Budapest, Hungary, 1999. Findings on unintentional and intentional injuries, alcoho use, and sexual activity. Cent Eur J Public Health. 2004 Jun;12(2):94-101.

17. Petrovic B, Kocic B, Basic S, Jovanovic J, Jovic S, Arandelovic M, et al. Suicide in the elderly 60 years of age and over in the south-east part of Serbia. Cent Eur J Public Health. 2004 Mar;12(1):21-5.

18. Blasszauer B, Hazafi K. Hungary as an aging society. Cent Eur J Public Health. 1994 Dec;2(2):115-7.

19. Jacobsen D, Frederichsen PS, Knutsen KM, Sørum Y, Talseth T, Odegaard OR. A prospective study of 1212 cases of acute poisoning: general epidemiology. Hum Toxicol. 1984 Apr;3(2):93-106.

Received October 20, 2008 Accepted in revised form February 12, 2009 